\title{
Short communication: Development and evaluation of equations to predict growth of Holstein dairy heifers in a tropical climate
}

\author{
A. L. Silva, ${ }^{1,2 *} \oplus$ T. J. DeVries, ${ }^{2} \oplus$ E. C. Fernandes, ${ }^{3}{ }^{\oplus}$ and M. I. Marcondes ${ }^{4}{ }^{\circ}$ \\ ${ }^{1}$ Department of Animal Production, Universidade Federal Rural do Rio de Janeiro, Seropédica, Rio de Janeiro 23897-000, Brazil \\ ${ }^{2}$ Department of Animal Biosciences, University of Guelph, Guelph, Ontario, N1G 2W1, Canada \\ ${ }^{3}$ Instituto Federal de Educação, Ciência e Tecnologia, Cruzeiro do Sul, Acre, 69980-000 Brazil \\ ${ }^{4}$ Department of Animal Science, Universidade Federal de Viçosa, Viçosa, Minas Gerais 36570-000, Brazil
}

\begin{abstract}
The objective of this study was to develop and validate equations for estimating growth of dairy heifers using measures of withers height, body weight (BW), and age. Measures of BW and withers height of 207 Holstein heifers raised in a tropical climate were taken from birth to calving, totaling to 2,047 observations. To be included in the database, the heifer had to have at least 4 measures recorded. After that, 4 models were built and evaluated as follows: (1) a linear model of BW as function of age (BW A), (2) a linear model of the $\mathrm{BW}$-to-height ratio as function of age $(\mathrm{BW}: \mathrm{H} \sim \mathrm{A})$, (3) a quadratic model, adjusted for a defined plateau, to describe height as function of age $(\mathrm{H} \sim \mathrm{A})$, and (4) an exponential growth model of BW as function of height $(\mathrm{BW} \sim \mathrm{H})$. A cross-validation procedure was performed to evaluate accuracy and precision of the models. The linear relationship of $\mathrm{BW} \sim \mathrm{A}$ and $\mathrm{BW}: \mathrm{H} \sim \mathrm{A}$ were estimated, respectively, by the equations: $\mathrm{BW}=42.65$ $+0.62 \times \mathrm{A}$ and $\mathrm{BW}: \mathrm{H}=0.70+0.0041 \times \mathrm{A}$, where $\mathrm{BW}$ is in kilograms, $\mathrm{BW}: \mathrm{H}=\mathrm{BW}$-to-height ratio $(\mathrm{kg} /$ $\mathrm{cm}$ ), and $\mathrm{A}=$ age (d). Using the quadratic plateau for the model $\mathrm{H} \sim \mathrm{A}$, a critical " $\mathrm{x}$ " value of $\sim 806 \mathrm{~d}$ and a height plateau of $138.6 \mathrm{~cm}$ were identified. Therefore, the following equations for estimating the height of animals younger and older than $806 \mathrm{~d}$, respectively, were developed: $\mathrm{H}=78.15+0.150 \times \mathrm{A}-0.00009 \times \mathrm{A}^{2}$ and $\mathrm{H}=78.15+0.150 \times \mathrm{cvx}-0.00009 \times \mathrm{cvx}^{2}$, where $\mathrm{H}$ $=$ height $(\mathrm{cm})$ and $\mathrm{cvx}=806$ (critical " $\mathrm{x}$ " value; given in days). Additionally, the exponential model of $\mathrm{W} \sim \mathrm{H}$ was estimated by the following equation: $\mathrm{BW}=4.25 \times$ $\exp ^{(0.034 \times \mathrm{H})}$, where $\mathrm{BW}$ is in kilograms and $\mathrm{H}=$ height $(\mathrm{cm})$. A cross validation demonstrated that all equations had very high accuracy and precision. Overall, these models demonstrated that BW and BW-to-height ratio increase linearly as a function of age, while BW
\end{abstract}

Received March 31, 2020.

Accepted August 19, 2020.

*Corresponding author: alexlopes@zootecnista.com.br follows an exponential growth pattern as a function of height. Additionally, the $\mathrm{H} \sim \mathrm{A}$ model predicted that heifers achieve a maximum height of $138.6 \mathrm{~cm}$ at 806 d of age.

Key words: age, body weight, height, body weight-toheight ratio

\section{Short Communication}

There is consensus among researchers, industry, and farmers that efficient rearing of heifers is required for the maintenance and growth of dairy herds (Le Cozler et al., 2008; Silva et al., 2018). The most common way to measure rearing-program efficiency is by using development targets; for instance, commonly reported targets are 60 to $65 \%$ of mature BW at breeding and 85 to $90 \%$ of the mature BW at first calving (NRC, 2001; Handcock et al., 2019a). Therefore, studying and understanding of growth curves are important for predicting heifer nutritional requirements, as well as to identify the best and worst animals of the herd, or even management failures (Williams and Jenkins, 2003). Heifer growth performance may affect reproduction and have long-term effects on milk yield up to third lactation (Bazeley et al., 2016; Handcock et al., 2019b). Furthermore, Handcock et al. (2020) demonstrated that heifer BW at 15 mo of age has an influence on the animal's stayability in herd at the first, second, and third calving, emphasizing the importance of growth measurements.

Despite the importance of growth measurement of dairy heifers, there is a lack of comprehensive information for these animals (i.e., BW, height, and age), with greater availability and emphasis of BW measures (Cue et al., 2012). Consequently, most predictions and evaluations of heifer growth are based solely on BW and age (Bazeley et al., 2016). Nevertheless, some researchers have demonstrated that, in addition to proper weight gain, the animal must also grow in stature (height) for proper development (Heinrichs and Losinger, 1998; Krpálková et al., 2014). In addition to BW and age, 
withers height may be an important metric of development, and thus also should be modeled (Cue et al., 2012).

Although some researchers have concurrently used measurements of BW and height to describe the development of growing heifers, these studies were conducted in countries with temperate climate and with different dairy cattle genetics (Heinrichs et al., 1992; Cue et al., 2012), which could limit the application of their models to tropical conditions. Additionally, other research has been performed with objectives other than modeling growth (Handcock et al., 2019a,c). Therefore, the objective of this study was to develop and validate equations for estimating growth of Holstein dairy heifers in a tropical climate using measures of withers height, BW, and age, and to demonstrate how these measurements may be used as tools to evaluate growth.

The animals used in this retrospective study originated from the Research Dairy Cattle Farm of Universidade Federal de Viçosa-Brazil (Viçosa, MG, Brazil), with data collected from 2010 to 2018. Measurements of 207 Holstein heifers were taken from birth to calving, totaling to 2,047 observations of BW and withers height. To be included in the database, the heifer had to have at least 4 separate records of BW and withers height. The maximum number of measurements per heifer was 21 (BW and withers height), with an average of 10.7 measurements per heifer. Overall, the data points were well distributed according to animal age, with $\sim 55 \%$ of the data collected before 12 mo of age and $\sim 45 \%$ after that. These measurements were part of the routine management of the Universidade Federal de Viçosa Research Dairy Cattle Farm and followed prescribed animal welfare protocols and recommendations
(Brasil, 2016). As this study used a previously collected database, a specific animal care and use protocol was not required.

During the data collection period, an average of 26 heifers were born per year at the research center; these heifers were reared in the preweaning phase in individual hutches. The animals had free access to water, starter feed, and forage source, with an average of 6 L/d of raw whole milk fed twice daily. The animals were weaned when they reached a starter feed intake of $1.2 \mathrm{~kg} / \mathrm{d}$, which generally occurred between 60 and 70 d of age. Calves were then moved to group pens $(\sim 10$ animals per pen) in a freestall facility and fed corn silage or chopped sugarcane as forage, plus concentrate adjusted to their nutrient requirements to target an ADG of $0.8 \mathrm{~kg} / \mathrm{d}$, according to NRC (2001). All heifers were submitted to this management until their first calving, which occurred at $24.9 \mathrm{mo}$ of age (minimum of $21.5 \mathrm{mo}$ and maximum of $36.5 \mathrm{mo}$ ) on average (Table $1)$.

Information on individual animal BW (kg) was taken using a weight scale, while measures of withers height $(\mathrm{cm})$ were taken using a hipometer in intervals of $60 \mathrm{~d}$ on average. Information about age (d) and calculated BW-to-height ratio $(\mathrm{kg}: \mathrm{cm})$ were extracted from the collated database. Descriptive statistics provided by growth phase (birth, 9 mo of age, and first calving) are provided in Table 1.

Four models that describe the growth of dairy heifers were evaluated as follows: (1) BW as a function of age $(\mathbf{B W} \sim \mathbf{A})$, (2) BW-to-height ratio as a function of age $(\mathbf{B W}: \mathbf{H} \sim \mathbf{A})$, (3) BW as a function of height $(\mathbf{B W} \sim \mathbf{H})$, and (4) height as a function of age $(\mathbf{H} \sim \mathbf{A})$. Initially, a graphical appraisal of these associations was

Table 1. Descriptive statistics of the data used to develop and evaluate the models to predict the growth of Holstein dairy heifers

\begin{tabular}{lcccccc}
\hline Item & $\mathrm{N}^{1}$ & Mean & Median & $\mathrm{SD}$ & Minimum & Maximum \\
\hline Birth & & & & & & \\
Weight, kg & 98 & 36 & 37 & 4.89 & 20 & 45 \\
Height, cm & 98 & 73 & 73 & 4.21 & 61 & 84 \\
W:H, ${ }^{2} \mathrm{~kg}: \mathrm{cm}$ & 98 & 0.48 & 0.49 & 0.062 & 0.33 & 0.59 \\
9 mo age & & & & & & 301 \\
Weight, kg & 108 & 228 & 223 & 20.8 & 212 & 128 \\
Height, cm & 108 & 115 & 114 & 3.6 & 105 & 2.55 \\
W:H, kg:cm & 108 & 1.99 & 1.97 & 0.164 & 1.88 & 675 \\
First calving & & & & & 456 & 149 \\
Weight, kg & 108 & 538 & 525 & 52.5 & 3.7 & 3.32 \\
Height, cm & 108 & 139 & 136 & 3.84 & 0.351 & 3.5 \\
W:H, kg:cm & 108 & 3.91 & 24.2 & 4.21 & 21.5 & 36.5 \\
Age, mo & 108 & 24.9 & 24.2 & & \\
\hline
\end{tabular}

${ }^{1} \mathrm{~N}=$ number of heifers (the description means that 98 of 207 heifers were measured for BW and withers height at birth, and 108 of 207 heifers were measured for BW and withers height at 9 mo age and first calving, but not necessarily the same animals).

${ }^{2} \mathrm{~W}: \mathrm{H}=$ ratio between weight and height of dairy heifers. 
performed to identify the patterns of the data and select some candidate functions. These functions were used to adjust the parameters of each model, following the methodology described below.

Both $\mathrm{BW} \sim \mathrm{A}$ and $\mathrm{BW}: \mathrm{H} \sim \mathrm{A}$ models were evaluated using simple mixed-effect linear regression, using the random effect of animal (heifer) in the intercept and slope of the final models. The $\mathrm{BW} \sim \mathrm{H}$ model was built using a mixed-effect growth exponential model, using animal (heifer) as a random effect, as follows:

$$
B W_{i j}=\left(\beta_{0}+\beta_{0 i}\right) \times \exp ^{\left(\left(\beta_{1}+\beta_{1 i}\right) \times H\right)}+\varepsilon_{i j}
$$

where $B W_{i j}=\mathrm{BW}(\mathrm{kg}), H=$ height $(\mathrm{cm}), \beta_{0}$ and $\beta_{1}$ are the equation parameters (fixed effects), $\beta_{0 i}$ and $\beta_{1 i}$ are the random effects of animal associated with each respective fixed effect and $\varepsilon_{i j}=$ random error associated with each observation.

To explain the response of $\mathrm{H} \sim \mathrm{A}$, a quadratic model was built with a defined plateau according to the methodology described by Mangiafico (2016). This model included animal (heifer) as a random effect, following the equations below:

$H_{i j}=\left(\beta_{0}+\beta_{0 i}\right)+\left(\beta_{1}+\beta_{1 i}\right) \times A+\left(\frac{-0.5 \times\left(\beta_{1}+\beta_{1 i}\right)}{c v x}\right) \times A^{2}+\varepsilon_{i j}$,

when $A<c v x$, and

$H_{i j}=\left(\beta_{0}+\beta_{0 i}\right)+\left(\beta_{1}+\beta_{1 i}\right) \times c v x+\left(\frac{-0.5 \times\left(\beta_{1}+\beta_{1 i}\right)}{c v x}\right) \times c v x^{2}+\varepsilon_{i j}$,

when $A>c v x$, where $H_{i j}=$ height $(\mathrm{cm}), A=$ age (d), $c v x=$ critical " $\mathrm{x}$ " value (which refers to the age from which there is no further increase in heifer height), $\beta_{0}$ and $\beta_{1}$ are the equation parameters (fixed effects), $\beta_{0 i}$ and $\beta_{1 i}$ are the random effects of animal associated with each respective fixed effect, and $\varepsilon_{i j}=$ random error associated with each observation. Alternatively, $\mathrm{H} \sim \mathrm{A}$ was evaluated using the recognized Brody (monomolecular) and Richards nonlinear models (Richards, 1959). For both models, heifer was included as random effect for all parameters of the equations (intercept and slope).

The estimation of fixed effects and variance components (Supplemental Table S1, https://doi.org/10 .3168/jds.2020-18624) of linear models was done using a linear mixed-effect model function, while the nonlinear model was adjusted using a nonlinear mixed-effect model function, both in the package "nlme" of R (R Core Team, 2019). For adjusting the quadratic plateau function, we also used the "rcompanion" and "psych" packages of R (Mangiafico, 2016; R Core Team, 2019). Observations with studentized residuals greater than $|2.5|$ were considered outliers (Tedeschi, 2006) and excluded from the database.

A cross-validation procedure was performed with 1,000 simulations, according to Efron and Tibshirani (1998), for evaluating the goodness of fit of the models. To perform this analysis, we used the nonlinear least squares function and "boot" and "mass" packages of R (R Core Team, 2019). Briefly, each simulation was performed by randomly splitting up the original database into 2 new equally-sized subsets. The first subset (training subset) was used to obtain the equation parameters, and the second subset (testing subset) was used to test the obtained parameters. After each simulation, the data set was reorganized, and the process was repeated 1,000 times to generate the average of the sensitivity statistics (Silva et al., 2019).

The results of the sensitivity analyses were used to access the accuracy and precision of the developed models by using the mean square error of prediction (MSEP), concordance correlation coefficient (CCC), and coefficient of determination $\left(\mathrm{R}^{2}\right)$. The MSEP was decomposed into mean bias, systematic bias, and random error, which represents the variation that is not explained by the regression (Tedeschi, 2006). The CCC was decomposed into the correlation coefficient estimate $(\boldsymbol{\rho})$, a precision indicator, and bias correction factor $\left(\mathbf{C}_{\mathbf{b}}\right)$, an accuracy indicator. Values close to 1 for $\mathrm{CCC}, \rho$, and $\mathrm{C}_{\mathrm{b}}$, (ranging from $0-1$ ) indicate precise and accurate models (Lin, 1989; Tedeschi, 2006).

Both the BW A (Equation 4; Figure 1A) and BW: $\mathrm{H} \sim \mathrm{A}$ (Equation 5; Figure 1B), models demonstrated a similar pattern, with a linear increase in these measurements as age increases, according to the following equations:

$$
\begin{gathered}
B W=42.66_{ \pm 1.711}+0.62_{ \pm 0.009} \times A \\
B W: H=0.706_{ \pm 0.015}+0.0041_{ \pm 0.00006} \times A,
\end{gathered}
$$

where $B W(\mathrm{~kg}), B W: H=\mathrm{BW}$-to-height ratio $(\mathrm{kg}: \mathrm{cm})$, and $A=$ age (d). These results clearly demonstrate that, for BW related measures, heifers are in an ascending phase of growth until their first calving, without demonstrating an asymptotic pattern. Therefore, in this case, it was more suitable to use linear models than nonlinear models such as Brody-type models (Cue et al., 2012). 
The model of $\mathrm{BW} \sim \mathrm{H}$ showed an exponential growth pattern (Figure 1C), as presented by the follow equation:

$$
B W=4.25_{ \pm 0.137} \times \exp ^{\left(0.034_{ \pm 0.0003} \times H\right)},
$$

where $B W$ is in kilograms, $H=$ height $(\mathrm{cm})$. The pattern of Equation 6 highlights the limitation of using linear equations for predicting $\mathrm{BW}$ as a function of height (Heinrichs et al., 1992).

The BW-to-height ratio is greater in the final stage of growth when the animal approaches its mature BW (Figure 1B). This result is related to the exponential relationship that exists between BW and height. Therefore, height gain in heifers is reduced incrementally as they get older, whereas their weight gain is almost constant. This is likely related to a higher fat deposition than in early life when the animals have greater muscle deposition (Marcondes et al., 2016).

It is interesting to note that the dispersions observed for both Equations 4 and 5 (Figure 1A and 1B) are lesser for young animals and greater for older ones (see standard deviations in Table 1). A similar pattern was observed by Cue et al. (2012) and Bazeley et al. (2016), and it is potentially linked to the growth rate of different body tissues. In early life, the bone structure of animals grows more proportionally, resulting in more consistent weight gain between animals during that time period (Owens et al., 1993).

The prediction of height for dairy heifers was performed using Equation 7 for animals younger than
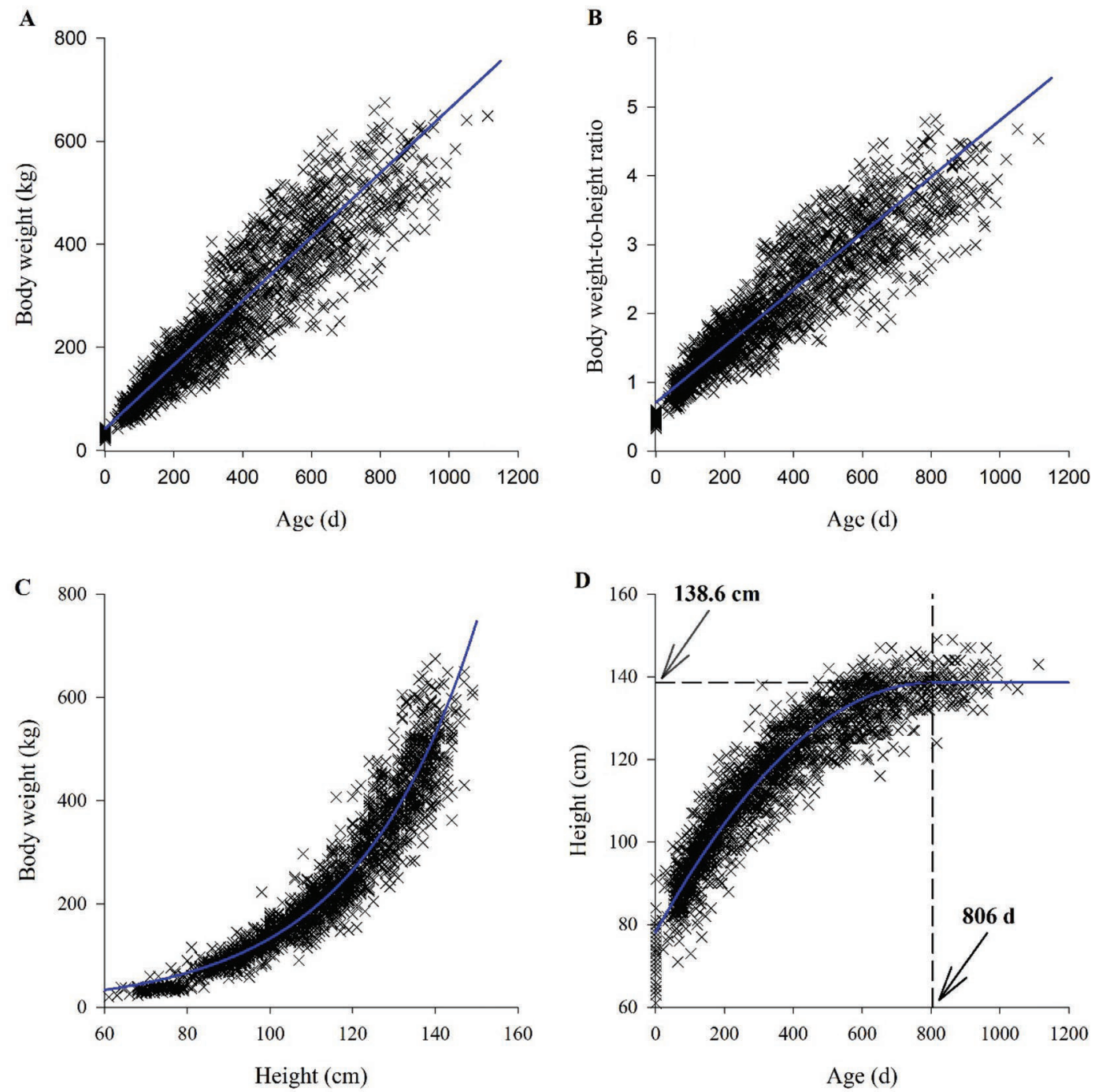

Figure 1. Observed data and fitted equations for BW as a function of age (A), body weight-to-height ratio as a function of age (B), BW as a function of height (C), and height as a function of age (D) for growing Holstein dairy heifers. 
$\sim 806 \mathrm{~d}$, and Equation 8 for animals older than $\sim 806 \mathrm{~d}$ of life as follows:

$$
H=78.15_{ \pm 0.400}+0.150_{ \pm 0.0018} \times A-0.00009_{ \pm 0.00001} \times A^{2}
$$

when $A<\operatorname{cvx}(806 \mathrm{~d})$, and

$$
H=78.15_{ \pm 0.400}+0.150_{ \pm 0.0018} \times c v x-0.00009_{ \pm 0.00001} \times c v x^{2},
$$

when $A>\operatorname{cvx}(806 \mathrm{~d})$, where $H=$ height $(\mathrm{cm}), A=$ age (d), cvx $=806$ (critical " $\mathrm{x}$ " value; given in $\mathrm{d}$ ). The critical " $x$ " value, which represents the age from which there is no further increase in heifer height, was demonstrated to be at $806 \mathrm{~d}$ of life. Our quadratic plateau equation indicated that heifers have greater height gain early in life, primarily before puberty (Figure 1D), which occurs in Holstein heifers around 9 to 10 mo of age (Davis Rincker et al., 2011; Silper et al., 2015). After puberty, the rate of height gain decreased until $\sim 806 \mathrm{~d}$ of age, when their heights stabilized at $138.6 \mathrm{~cm}$ (Figure 1D). Val et al. (2004) reported a similar result, with a height plateau of $140 \mathrm{~cm}$ for Holstein heifers at the age of $\sim 790 \mathrm{~d}$ reared in Brazil in the 1990s. Alternatively, Cue et al. (2012) estimated the mature height for Holstein heifers reared in Canada to be $\sim 148$ $\mathrm{cm}$, which was reached at $\sim 700 \mathrm{~d}$ of life. Duplessis et al. (2015), also in Canada, estimated a mature height of $\sim 149 \mathrm{~cm}$ around $810 \mathrm{~d}$ of life $(27 \mathrm{mo})$, which was presented by the authors as the mean age at calving in that country at that time. Overall, our current data and these previous studies demonstrate that withers height is, apparently, stabilized around first calving and only BW continues to grow after this moment (Figure 1A). However, our database did not include records of older animals (first, second, and third lactations) to confirm this pattern. Additionally, the difference between mature height found in Canada and Brazil is likely due to breeding programs used in Brazil, which have been designed to select for smaller animals than in North America (Oliveira et al., 2013).

Concerning the estimates of the nonlinear models of Brody and Richards, they produced similar results to those proposed using quadratic plateau equations until $\sim 780$ to 790 d old (Supplemental Figure S1, https:/ /doi.org/10.3168/jds.2020-18624). However, for both the Brody and Richards models the determination of height at maturity and, mainly, the age in which height at maturity occurs were overestimated. For Brody's model, the height at maturity was estimated as $149 \mathrm{~cm}$, while for Richards's model this value would be $152 \mathrm{~cm}$ (beyond the domain of the data, where the maximum observation was $149 \mathrm{~cm}$ ). Furthermore, both models estimated that the mature height would be achieved at $\sim 10$ yr of age, which is biologically incoherent. However, it is important to highlight that if the database was composed of records throughout the lifetime of animals, the good-of-fit of nonlinear models would be improved.

These results support the recommendation that measurement of weight and height, rather than just weight, may be important for better evaluation of heifer development (Cue et al., 2012). Current recommendations suggest that the target $\mathrm{BW}$ at breeding is $\sim 60 \%$ of mature weight (Handcock et al., 2019b), which is equivalent to $\sim 330$ to $340 \mathrm{~kg}$ for Holstein heifers reared in Brazil (Marestone et al., 2013). Therefore, the adoption of the equations presented in this study may guide rearing-program decisions, particularly for breeding. As an application of the proposed equations, considering a BW at breeding of $\sim 340 \mathrm{~kg}$, the use of the exponential equation of $\mathrm{BW} \sim \mathrm{H}$ (Equation 6) indicated that height at breeding would be $127 \mathrm{~cm}$. Additionally, it is predicted that heifers should achieve this height around $452 \mathrm{~d}(\sim 15 \mathrm{mo})$ of age when using the result $(127 \mathrm{~cm})$ in Equation 7. Hence, it is possible to monitor heifer growth, comparing herd results with standard targets.

The cross-validation analysis demonstrated that all equations had very high accuracy (Table 2), as all of the values of $C_{b}$ were 0.99 . In the same way, the precision, indicated by the $\mathrm{R}^{2}$ and $\rho$, was high for all equations, and primarily for $\mathrm{BW} \sim \mathrm{H}$ and $\mathrm{H} \sim \mathrm{A}$ (Table 2 ). The lower precision of the $\mathrm{BW} \sim \mathrm{A}$ and $\mathrm{BW}: \mathrm{H} \sim \mathrm{A}$ models, when compared with the other equations, was likely due to the dispersion of these measures in older animals, as described above and reported by Cue et al. (2012). For all equations, the majority of the MSEP was associated with random effects ( $>99 \%$; Table 2$)$; this, in association with their high accuracy, demonstrates the models' abilities to predict both actual and precise values (Tedeschi, 2006; Silva et al., 2019).

In conclusion, the relationship between BW and BWto-height ratio, as a function of age of Holstein dairy heifers, was estimated by linear equations. The dispersion of these measures was lower for animals up to the age of puberty. Additionally, the height of dairy heifers for a determined age was estimated by a quadratic plateau equation, where heifers achieve a maximum height of $138.6 \mathrm{~cm}$ at $806 \mathrm{~d}$ of age. Moreover, weight followed an exponential growth pattern as a function of height. Overall, all of the developed equations demonstrated very high accuracy and high precision, having great potential to predict the growth of dairy heifers. 
Table 2. Adequacy parameters of the equations developed to predict growth of Holstein dairy heifers obtained through cross-validation technique

\begin{tabular}{|c|c|c|c|c|}
\hline \multirow[b]{2}{*}{ Item $^{2}$} & \multicolumn{4}{|c|}{ Equation $^{1}$} \\
\hline & $\mathrm{BW} \sim \mathrm{A}$ & $\mathrm{BW}: \mathrm{H} \sim \mathrm{A}$ & $\mathrm{BW} \sim \mathrm{H}$ & $\mathrm{H} \sim \mathrm{A}$ \\
\hline \multicolumn{5}{|l|}{ Partition of MSEP (\%) } \\
\hline Mean bias & 0.046 & 0.053 & 0.135 & 0.049 \\
\hline Systematic bias & 0.060 & 0.066 & 0.346 & 0.047 \\
\hline Random eror & 99.894 & 99.881 & 99.519 & 99.904 \\
\hline CCC (ranging from 0 to 1 ) & 0.924 & 0.909 & 0.951 & 0.954 \\
\hline$\rho$ & 0.927 & 0.913 & 0.954 & 0.955 \\
\hline $\mathrm{C}_{\mathrm{b}}$ & 0.997 & 0.995 & 0.997 & 0.999 \\
\hline $\mathrm{R}^{2^{\mathrm{D}}}$ & 0.859 & 0.834 & 0.908 & 0.912 \\
\hline
\end{tabular}

${ }^{1} \mathrm{BW} \sim \mathrm{A}=$ equation of body weight in function of age; $\mathrm{BW}: \mathrm{H} \sim \mathrm{A}=$ equation of body weight-to-height ratio in function of age; $\mathrm{BW} \sim \mathrm{H}=$ equation of body weight in function of height; $\mathrm{H} \sim \mathrm{A}=$ equation of height in function of age.

${ }^{2} \mathrm{MSEP}=$ mean square error of prediction; $\mathrm{CCC}=$ concordance correlation coefficient; $\rho=$ correlation coefficient estimate; $\mathrm{C}_{\mathrm{b}}=$ bias correction factor.

\section{ACKNOWLEDGMENTS}

The authors thank the following Brazilian foundations: Coordenação de Aperfeiçoamento de Pessoal de Nível Superior (CAPES), Conselho Nacional de Desenvolvimento Científico e Tecnológico (CNPq), Fundação de Amparo à Pesquisa do Estado de Minas Gerais (FAPEMIG), and Instituto de Ciência e Tecnologia de Ciência Animal (INCT-CA). The authors have not stated any conflicts of interest.

\section{REFERENCES}

Bazeley, K. J., D. C. Barrett, P. D. Williams, and K. K. Reyher. 2016. Measuring the growth rate of UK dairy heifers to improve future productivity. Vet. J. 212:9-14. https://doi.org/10.1016/j.tvjl.2015 .10 .043 .

Brasil, Ministério da Ciência, Tecnologia, Inovações e Comunicações. 2016. Normativas do CONCEA para produção, manutenção ou utilização de animais em atividades de ensino ou pesquisa científica. 387 p. Accessed Jan. 20, 2020. https://www.ceua.ufv.br/wp -content/uploads/2018/08/NORMATIVAS-DO-CONCEA-3\%C2 \%AA-EDI\%C3\%87\%C3\%83O2.pdf.

Cue, R. I., D. Pietersma, D. Lefebvre, R. Lacroix, K. Wade, D. Pellerin, A. M. de Passillé, and J. Rushen. 2012. Growth modeling of dairy heifers in Québec based on random regression. Can. J. Anim. Sci. 92:33-47. https://doi.org/10.4141/cjas2011-083.

Davis Rincker, L. E., M. J. VandeHaar, C. A. Wolf, J. S. Liesman, L. T. Chapin, and M. S. Weber Nielsen. 2011. Effect of intensified feeding of heifer calves on growth, pubertal age, calving age, milk yield, and economics. J. Dairy Sci. 94:3554-3567. https://doi.org/ 10.3168/jds.2010-3923.

Duplessis, M., R. I. Cue, D. E. Santschi, D. M. Lefebvre, and R. Lacroix. 2015. Weight, height, and relative-reliability indicators as a management tool for reducing age at first breeding and calving of dairy heifers. J. Dairy Sci. 98:2063-2073. https://doi.org/10.3168/ jds.2014-8279.

Efron, B., and R. J. Tibshirani. 1998. An Introduction to the Bootstrap. Chapman \& Hall/CRC, Boca Raton, Florida.

Handcock, R. C., C. M. C. Jenkinson, R. Laven, L. R. McNaughton, N. Lopez-Villalobos, P. J. Back, and R. E. Hickson. 2019a. Linear versus seasonal growth of dairy heifers decreased age at puberty but did not affect first lactation milk production. N. Z. J. Agric. Res. 0:1-18. https://doi.org/10.1080/00288233.2019.1607404.
Handcock, R. C., N. Lopez-Villalobos, L. R. McNaughton, P. J. Back, G. R. Edwards, and R. E. Hickson. 2019b. Positive relationships between body weight of dairy heifers and their first-lactation and accumulated three-parity lactation production. J. Dairy Sci. 102:4577-4589. https://doi.org/10.3168/jds.2018-15229.

Handcock, R. C., N. Lopez-Villalobos, L. R. McNaughton, P. J. Back, G. R. Edwards, and R. E. Hickson. 2019c. Live weight and growth of Holstein-Friesian, Jersey and crossbred dairy heifers in New Zealand. N. Z. J. Agric. Res. 62:173-183. https://doi.org/10.1080/ 00288233.2018.1465984.

Handcock, R. C., N. Lopez-Villalobos, L. R. McNaughton, P. J. Back, G. R. Edwards, and R. E. Hickson. 2020. Body weight of dairy heifers is positively associated with reproduction and stayability. J. Dairy Sci. 103:4466-4474. https://doi.org/10.3168/jds.2019-17545.

Heinrichs, A. J., and W. C. Losinger. 1998. Growth of Holstein dairy heifers in the United States. J. Anim. Sci. 76:1254-1260. https:// doi.org/10.2527/1998.7651254x.

Heinrichs, A. J., G. W. Rogers, and J. B. Cooper. 1992. Predicting body weight and wither height in Holstein heifers using body measurements. J. Dairy Sci. 75:3576-3581. https://doi.org/10.3168/ jds.S0022-0302(92)78134-X.

Krpálková, L., V. Cabrera, M. Vacek, M. Štípková, L. Stádník, and P. Crump. 2014. Effect of prepubertal and postpubertal growth and age at first calving on production and reproduction traits during the first 3 lactations in Holstein dairy cattle. J. Dairy Sci. 97:3017-3027. https://doi.org/10.3168/jds.2013-7419.

Le Cozler, Y., V. Lollivier, P. Lacasse, and C. Disenhaus. 2008. Rearing strategy and optimizing first-calving targets in dairy heifers: A review. Animal 2:1393-1404. https://doi.org/10.1017/ S1751731108002498.

Lin, L. I. 1989. A concordance correlation-coefficient to evaluate reproducibility. Biometrics 45:255-268. https://doi.org/10.2307/ 2532051.

Mangiafico, S. S. 2016. Summary and Analysis of Extension Program Evaluation in R. version. No. 1.18.1. Accessed Jan. 20, 2020. https: //rcompanion.org/handbook/index.html.

Marcondes, M. I., L. O. Tedeschi, S. C. V. Filho, L. F. Costa e Silva, and A. Lopes da Silva . 2016. Using growth and body composition to determine weight at maturity in Nellore cattle. Anim. Prod. Sci. 56:1121-1129. https://doi.org/10.1071/AN14750.

Marestone, B. S., É. R. dos Santos, F. B. S. Serra, C. A. D. S. D. Muniz, C. P. Marques, K. B. Alves, M. V. Alves, and R. C. M. Alves. 2013. Características reprodutivas, de crescimento e idade ao primeiro parto em bovinos da raça Holandesa. Semina Ciênc. Agrár. 34:4105. https://doi.org/10.5433/1679-0359 .2013v34n6Supl2p4105.

NRC. 2001. Nutrient Requirements of Dairy Cattle. 7th ed. National Academy Press, Washington, DC. 
Oliveira, A. S., D. C. Abreu, M. A. Fonseca, and P. M. B. Antoniassi. 2013. Development and evaluation of predictive models of body weight for crossbred Holstein-Zebu dairy heifers. J. Dairy Sci. 96:6697-6702. https://doi.org/10.3168/jds.2013-6988.

Owens, F. N., P. Dubeski, and C. F. Hanson. 1993. Factors that alter the growth and development of ruminants. J. Anim. Sci. 71:31383150. https://doi.org/10.2527/1993.71113138x.

R Core Team. 2019. R: A Language and Environment for Statistical Computing. R Foundation for Statistical Computing, Vienna, Austria.

Richards, F. J. 1959. A flexible growth function for empirical use. J. Exp. Bot. 10:290-301. https://doi.org/10.1093/jxb/10.2.290.

Silper, B. F., I. Robles, A. M. L. Madureira, T. A. Burnett, M. M. Reis, A. M. de Passillé, J. Rushen, and R. L. A. Cerri. 2015. Automated and visual measurements of estrous behavior and their sources of variation in Holstein heifers. I: Walking activity and behavior frequency. Theriogenology 84:312-320. https://doi.org/ 10.1016/j.theriogenology.2014.12.029.

Silva, A. L., E. Detmann, J. Dijkstra, A. M. Pedroso, L. H. P. Silva, A. F. Machado, F. C. Sousa, G. B. dos Santos, and M. I. Marcondes. 2018. Effects of rumen-undegradable protein on intake, performance, and mammary gland development in prepubertal and pubertal dairy heifers. J. Dairy Sci. 101:5991-6001. https:// doi.org/10.3168/jds.2017-13230.
Silva, A. L., T. J. DeVries, L. O. Tedeschi, and M. I. Marcondes. 2019. Development of equations, based on milk intake, to predict starter feed intake of preweaned dairy calves. Animal 13:83-89. https:// doi.org/10.1017/S1751731118000666.

Tedeschi, L. O. 2006. Assessment of the adequacy of mathematical models. Agric. Syst. 89:225-247. https://doi.org/10.1016/j.agsy .2005.11.004.

Val, J. E., M. A. R. Freitas, H. N. Oliveira, V. L. Cardoso, P. F. Machado, and J. C. C. Paneto. 2004. Productive indicator in a Holstein dairy herd: Growth and height curves, reproductive and productive traits and genetic parameters. Arq. Bras. Med. Vet. Zootec. 56:86-93. https://doi.org/10.1590/S0102-09352004000100014.

Williams, C. B., and T. G. Jenkins. 2003. A dynamic model of metabolizable energy utilization in growing and mature cattle. II. Metabolizable energy utilization for gain. J. Anim. Sci. 81:1382-1389. https://doi.org/10.2527/2003.8161382x.

\section{ORCIDS}

A. L. Silva @ https://orcid.org/0000-0002-3288-4387

T. J. DeVries @ https://orcid.org/0000-0001-9364-2456

E. C. Fernandes (ㄴ) https://orcid.org/0000-0001-5882-7105

M. I. Marcondes () https://orcid.org/0000-0003-4843-2809 